Original Research Paper

\title{
The State of Social and Strategic Planning in Spatial Terms (Case Study: Developing Countries), Analytical Study
}

\author{
Khalil Abu Allan and Hassan Qaddumi* \\ Department of Applied Geography, Hebron University, Palestine
}

\author{
Article history \\ Received:18-11-2019 \\ Revised: 20-01-2020 \\ Accepted: 12-02-2020 \\ Corresponding Author: \\ Hassan Qaddumi \\ Department of Applied \\ Geography, Hebron University, \\ Palestine \\ Email: Hassanq@hebron.edu
}

\begin{abstract}
Through this study, which showed the important role of social planning and clarify the concept and intent of social planning and the stages of this planning, through a critical and analytical study, based on the sequential, analytical and comparative approach. Through which society is developed, individuals are activated in development. The study also found that the developing countries still suffer from weakness in their strategic and development plans due to political, economic and social factors. The study concluded that these countries should be developed and the importance of implementing social and strategic plans in order to reach sustainable development, it was found that pumping $90 \%$ of developing countries suffer from a lack of planning services in all its forms, due to social, economic and political factors.
\end{abstract}

Keywords: Social Planning, Strategic Planning, Development, Determinants, Developing Countries

\section{Introduction}

The contemporary world community is divided into two groups of countries: One is called the rich or developed, the other is the developing. The division of societies into developed and underdeveloped is not true because there is no confinement of countries in this area because there are wealth in some countries that can make development. There are differences between developing societies in terms of income level, natural resources, demographic composition, nature of social organization, or the civilization stage they are under.

The importance of this study lies in analyzing the reality of social and strategic planning in the recent time period, as this topic is in the regions of developing countries and it is not focused much on it. This study came to show the importance of this topic, relying on an analytical and critical style.

This research accurately illustrates the evolution of the concept of social planning and its importance in societies, especially developing countries, or countries that are at the beginning of social progress and development, by tracking developments on social development and its applications, this research also focuses on the principles of social planning and the bases on which rely, the impact of these standards on development plans and sustainable development and the most important types of social planning, long-term and medium-term, short-term and stages of implementation.
The research presents the subject of strategic planning at the local and external levels and the impact of internal administrative factors on the implementation of the strategic plans of the countries, as well as the political factor, which is one of the most important factors affecting the strategic role of States and internal and external institutions and obstacles affecting strategic planning and its impact on policies. Developmental institutions and countries.

This study also shows the situation of developing countries and the problems they suffer from, especially the reality of planning in these countries, among the most important of these problems is economic imbalance and mismanagement, where these countries suffer from weak management of their economic resources and services, due to political dependency, (Whelan, 2018). The influence and control of developed countries on the resources of developing countries and the absence of domestic policies that control social plans, all led to the emergence of a vacuum in society.

\section{Social Planning Between Concept and Progressive Development}

Social planning is the path through which policymakers, legislators, government agencies, planners and often financiers try to solve community problems or improve conditions in the community through policymaking and implementation of specific outcomes. These 
policies can take the form of laws, regulations, incentives, media campaigns, services or information, a wide range of possibilities. The community or National Health Council, which adopts a law banning smoking in certain places, for example, is trying to protect the public from second-hand smoke on the one hand and to reduce smoking in general, on the other.

There is a long history of social planning in the United States and elsewhere. Traditionally, this meant that policymakers decided what they considered good for the community or the population and imposed a policy with the intention of producing the results they wanted. In the best cases, this meant programs that would benefit a large number of people. Such as President Franklin D. Roosevelt's New Decade program, the "Home Beginning" program in the United States and other public health programs. In the worst cases, social planning has been used for the economic or political benefit of policymakers, their friends and their supporters.

In other cases, planning has had negative consequences despite its good intentions. For example, urban renewal in the 1950 s and 1960 s, by cleaning up the "miserable" neighborhoods. Making cities better places to live safer, more attractive and more economically healthy (Kansas UN, 2017). In fact, this effect has mostly only affected people who have moved into new housing and new businesses, after they were residents.

Planning has recently become the key to success for the future and the achievement of goals in societies and countries across their political systems and addresses the various problems and obstacles to achieving a better level, regardless of their progress or under development. Social planning is based on the social philosophy of the community, making its meaning more comprehensive and broad to include various types of planning, such as health, economic, educational, urban and many other types of planning, which includes all aspects of human life.

Social planning is one of the scientific methods used by the social work profession to make deliberate social changes-it includes a set of procedures that regulate its work and is based on technical processes carried out by experts, technicians and social planners in collaboration with members of the community and its leaders through planning organs at different geographical and functional levels Within the framework of the overall development plan of society and within the prevailing ideology (Khalil, 2011a).

Social work as a career depends on social planning as the most appropriate way to choose the methods used in professional work aimed at solving problems and meet the needs of the community and the social worker in his work with any equipment of professional intervention (individual-group-community-organization) needs to plan as a method Scientific Success of his professional intervention ensures that students of social service provide the knowledge and skill base associated with social planning, so we hope that this work contributes to achieve this (Ahmed, 2007). The concept of development has several definitions, but it is a process of cultural change aimed at advancing society economically, technically, socially and culturally and employing all the material, natural and human resources of society for the benefit of all.

The concept of development was defined in the United Nations in 1956 as "processes by which citizens and the government can unite to improve economic, social and cultural conditions in local communities and to help them integrate into the life of the nation. It is a deliberate process that seeks to provide basic services to individuals; that is, it seeks to improve the conditions of individual and community life and is a parallel and equal process linked to the creation of new and evolving situations in all areas. Fields.

\section{Principles of Social Planning in the Development of Society}

- Conducting a comprehensive study of the society with a view to knowing its problems and needs

- Participation of parents in identifying those problems and needs

- Develop appropriate plans to face these problems and satisfy the needs with the participation of the people in the development of the line despite the technical aspects of planning

- Obtaining political approval of the proposed plans, which gives it a legal and legal dimension and financial support from the state, a condition that is a basis for its success

- Legislation on the implementation of plans to become positive

- The implementation of plans, which is an attempt to link the available resources, which can be made available to the problems and needs of the community with the broad participation of the planning body and the people

- Follow-up the implementation of plans and the follower preferably be during the implementation of plans to identify the problems and obstacles facing implementation and work to avoid them directly

- Evaluation and after the completion of the implementation of plans to determine the results of the plans, whether they have achieved the objectives for which they were set or failed to do so, usually after one year, two years of implementation and is trying to compare costs with the benefits achieved as the results of plans. If the benefits are greater than the costs, it means the success of the plans and vice versa if the costs and efforts exerted on the plans are higher than the benefits, it means the failure of the plans (Quraishi, 2011) 


\section{Types of Planning According to Applied Performance}

\author{
Planning has Several Types Divided by Several \\ Criteria, Including
}

\section{By Time Range}

Long-term planning: A planning that covers a period of more than five years and is shared by all managers where all the fields of starch are concentrated in the institution

Medium-term planning: A planning that covers a period of less than five years and is carried out by members of the middle management, as it is a way to overcome obstacles to planning and term.

Short-term planning: A planning that covers a period of less than a year where, it contains detailed plans of long-term planning and for the purpose of solving problems when they occur.

\section{Planning by Impact Range}

Strategic Planning: Strategic planning is defined as identifying the main long-term objectives of the organization and drawing plans and allocating the resources available to the organization in a way that can achieve these goals within the opportunities and constraints of the environment of the organization. Supreme and its impact is far and exemplified: Planning to add a new product line or planning to open a new market.

Tactical planning: It aims to support the strategic planning of the institution and is interested in assessing the validity of different alternatives of objectives and strategies and propose new ones, (Hamza, 2019) as it is characterized by flexibility in the selection and review of alternatives and exercised by the middle management and its medium-term impact, for example: Certain market.

Operational planning: It is the responsibility of the minimum management and is determined by the details of tactical planning by drawing a line of recurring activities in the organization and measurable in the form of forecasts and operational plans are placed in the form of budgets and estimates criteria to allow the determination of results in a clear and may be these budgets Monthly, weekly or daily and therefore assesses the implementation of the plan of the two types in the form of figures and values, such as: Identify the needs of production management of materials and spare parts.

Planning by function: Since the institution includes several activities related to the nature of its work and objectives, there are functions to be planned: production, sale, finance, catering.

Output Planning: Defined as: "making a prediction to develop a plan that includes all the steps that follow the production processes in the way that the planned objectives can be achieved".
Therefore, production planning is a process of predicting all stages of production and their needs to reach the objectives set.

Financial Planning: Interested in how to obtain funds from several parties with the least effort and cost.

Sales Planning: The company skips sales and its first goal is to find the best way to dispose of the goods produced, where we study the most important points of sale and the most important dealers who ensure the promotion of the product at the lowest cost. (Qasim, 2016), Supply planning: It is the process of estimating the materials and supplies needed by the institution in the light of its capabilities.

\section{Social Planning Stages (Planning and Implementation)}

The preparation of the plan is in fact only a stage of social planning and social planning goes through a number of stages as follows:

1. Preparation phase of the plan

2. The stage of monitoring its implementation and follow-up

3. The stage of evaluation and preparation for the development of the new plan

\section{First: Preparing the Plan}

This phase aims to prepare an integrated plan to meet the needs of the comprehensive plan for economic and social development, but it can be said that the preparation of a plan requires the following plan:

\section{Determine the General Objectives of the Plan}

1. study of reality and the most important characteristics

2. Estimating the needs of social services in the fields

3. Determining the extent of quantitative growth in the social services sector

4. Identify structural and professional changes

5. Estimate the cost of the plan

6. Determining the means of implementing the plan

\section{Second: Implementation and Follow-up Plan}

When the plan is completed and approved by the responsible authorities, the implementation phase and implementation of the plan is the responsibility of the implementing agencies. However, the follow-up of the implementation of the plan rests with the follow-up bodies, which bear the responsibility of following up the implementation to ensure that implementation is in accordance with the plan. Within the framework of a single body, the follow-up process is a time-bound identification of the implementation steps in accordance with the objectives and bases laid down on the extent of financial and temporal conformity as previously agreed in the plan. 


\section{Third: Evaluation and Preparation Phase of the New Plan}

The evaluation of the plan represents the final stage of social planning. It is a final statement of the success of the plan or not according to the goals set by the planners before the plan. After the completion of the implementation of all parts so as to spend an appropriate period is enough to judge the results of the implementation of the plan in the light of its general and detailed objectives.

Evaluate the plan or the way to develop new plans in the light of the experience gained from previous plans so that the new plan is more realistic and changeable and more fulfilling the needs of society (Aloni, 2019).

\section{Scientific Determinants of Social Planning to Reach Evolution}

There are several scientific determinants that must be taken into account when trying to build a plan, whether this plan at the national or local level of the most important of these determinants are the following:

1. Social planning is closely related to the prevailing factors of social and economic change, such as population growth and industrialization. These factors vary from country to country and even from sector to sector, with which needs to be studied in detail among all strata of the population

2. The plan must be flexible and coordinated with the circumstances of the society, which is characterized by continuous change and therefore must be in line with the requirements of modernization and requirements

3. It should be taken into consideration that the population, social, economic and administrative factors are all related or closely related. A large unit is inseparable, social planning must take into account the economic plan and the financial possibilities of the state

4. Social goals are built alongside economic goals and so within the framework of general planning of the state, (PST, 2016)

\section{Strategic Planning in Terms of Interactive Role}

Strategic planning is a long-term planning that takes into account internal and external variables and identifies the sectors, target market segments and method of competition. The answer to the question "Where are we going" taking into account the future vision of the company and the relationship and integration between the aspects of the organization and various activities and the relationship between the organization and its environment The future and prepare for it.

\section{The Stages of Strategic Planning}

\section{Preparation Phase}

Assuming the increased risk that surrounds the enterprise as a whole and with the increasing burden of competition imposed by successive development, it is necessary to prepare well for the future of the establishment and to set the optimum vision for what it should be to overcome the obstacles that may face it and to overcome the risks and draw a better future for them, so included the preparation phase Strategic planning has several steps.

\section{Strategic Analysis}

Strategic planning is based on a comprehensive systematic analysis of the Organization's current competitive position through current and anticipated opportunities and threats in the Organization's business environment and on the strengths and weaknesses within the organization, the analysis phase requires the gathering of a wealth of data and background information to help make the right decisions. The realities of the planners will certainly influence the attitudes towards the decision.

\section{Strategy Formulation}

The strategy is defined as: "A declaration of intent and a determination of what it wants to be in the long term. This requires knowledge of all the processes involved in order to avoid potential pitfalls. (DD, 2017) The strategy is the means to achieve long-term goals and is also known as the "pattern of objectives, objectives and programs, policy work, decisions, plans and resource allocation".

\section{Elements and Factors Affecting Strategic Analysis}

Management factors: Social responsibility, using strategic plans and strategic analysis, assessing and predicting environmental factors, rapid response to changing conditions (University Dynamics), flexibility of the University's organizational structure, efficiency of communication system and speed of information in the University, ability to persevere and deal with crises with creative abilities, the ability to adapt to technological changes, (LS, 2019). the ability to deal with the effects of inflation and the flexibility to deal with environmental variables.

Political/legal factors: Trade protection instructions, environmental protection laws, tax laws, special incentives, foreign trade instructions, direction to foreign companies, employment laws, government stability, trends of the ruling regime, other parties in the political arena, stakeholders, the state's relationship with the outside world, historical circumstance. 
Financial factors: Sources of capital, capital utilization, market exit, return on investment, liquidity, financial stability, ability to use prices as a competitive weapon, ability to expand to meet increasing demand, average costs, ability to pay short-term liabilities, ability to Repayment of long-term liabilities.

Economic factors: Trends of GNP, interest rates, money supply, inflation, unemployment, wage, price and tuition control, currency appreciation and devaluation, energy availability and cost, per capita income level, competition, suppliers, alternative services such as distance education and community colleges.

Human Factors: Experiences and administrative qualification, capabilities and trends, motivation and enthusiasm, possibilities, level of rehabilitation, rehabilitation possibilities.

Social, cultural, educational and cultural factors: Change in lifestyle, professional attitudes, consumer activity, family formation rate, age distribution of population, regional population transformation, life expectancy and population growth rate, birth rates, value systems, educational and cultural levels, cultural legacies.

Technological factors (physical and productive): Technical and technological skills, use of resources, level of technology used in educational services, (Ameri, 2005) ability to evaluate innovations in products and processes, production efficiency, product value added, economies of scale, factory modernity, computer use, effectiveness of training programs, ability to transfer ideas to application

\section{Planning in the Communities of Developing Countries}

The world in general and developing countries in particular, are increasingly interested in planning, recognizing that achieving the goals of transition to a better life must be linked to sound planning. The concept of planning has entered the field of economic and social life and economic planning has become a development factor for the economy and an approach to its management, because it is the scientific method of organizing the optimal investment of natural resources and human capacities in the integration and harmonization of the overall. The economic-administrative region is currently in the process of forming the local sectorial administration as an important link for regional planning.

Functional overlap is evident on the ground between central planning bodies (Supreme Planning Commission), ministries (central authorities) and local bodies (local governing bodies), making their work complementary to the development of an integrated regional plan aimed at the formation of integrated spatial economic systems According to the theory of production cycles of raw material and kinetic energy, (Khalil, 2011b) which makes the best investment of the natural and human resources available for the greatest economic and social efficiency possible. This is evident in the typical economic system the River of el-Bared region in the Ghab region.

Developing countries face many development challenges posed by the urgent needs of their populations internally, competing or comparing them with similar countries wishing to progress on the one hand and developed countries on the other. Population growth in these developing countries is witnessing an unprecedented development, as shown in the Human Development Report 2013. (United Nations website) Saudi Arabia is no exception. There is a population growth rate of $2.55 \%$ as shown by the Department of Statistics and Information. A major challenge to all aspects of development in the country.

If you talk about a population of $(30,770,375)$ people, you expect a population increase (total, not net) by $(784,644)$ and we can imagine the volume of additional services needed by this number and if we add that the services were not already completed for the previous numbers it shows us the size The challenge of covering the shortage of existing services and the need for existing services to update, change and maintain, (RNB, 2017) In addition to the increase resulting from the large and steady increase in the population, which requires an increase in all services in all aspects of life.

\section{Planning Problems in Developing Countries}

\section{Problems Related to Economic Development}

A. Increased rates of population growth in developing countries with a low proportion of people participating in economic activity

B. The acute shortage of national cadres in developing countries as a result of the lack of suitable employment opportunities for them, which forces them out to other countries. Many scientists in developing countries have come out looking for better jobs, better conditions and a more secure future for their children, especially from developing countries that are exposed to armed conflict or instability

C. The variation in the degree of development among the developing countries and this is evident through the economic indicators in each country

Many developing countries suffer from weak industrial production, indebtedness, unemployment, low savings, income inequality and low average incomes

D. Economic development in developing countries has long been dependent on world countries and has not yet taken an independent and influential course in the economy 
- $\quad$ Problems related to political development: The most prominent of these problems characterize most of the governments of developing countries as monopoly of power and therefore the majority of developing countries governed by political elites monopolize political power and all aspects of economic, social and cultural life (Zu'bi, 2018). The people are far from democratic participation in political life, which always disrupts the issue of political development in developing countries

In most developing countries there is a lack of clear ideological coordination that is in line with the requirements of social and political construction, weak national construction, lack of citizenship due to poor awareness and political culture and weak institutional structure of political structures. In addition to the spread of the phenomenon of political corruption through the lack of elite in achieving justice in the distribution of economic resources available.

Problems related to social development: The most prominent of these problems is the problem of weak collective participation in development plans because of the dominance of a certain group on development projects and thus they always seek to retain their position for as long as possible and monopolize privileges and shift the benefit of economic and social projects in their favor, in addition to centralization in taking Decisions made at the higher levels without taking into account persons at the lower levels (Hamo, 2016).

In addition, illiteracy, low health, high mortality, high birth rates, child labor and the absence of women's role in the productive process.

\section{Conclusion}

It has been shown through research that social planning should be among the priorities of countries and institutions, because it is considered one of the important pillars of development, through activating the role of society in maintaining cohesion and management of human and natural resources, in order to reach progress and economic development, The study also shows that the system of strategic plans must be activated for institutions within the state and that this plan is considered a path to be preserved for the people.

In addition to the problems facing the developing world since the early 1990 s as a result of the rapid dynamics of international events after the collapse of the Soviet Union and increased pressure facing these countries by international organizations aimed at reducing the role of the public sector in economic activity and freeing developing economies from all forms of restrictions and thus open their markets in front of foreign competition. The Western world has also undergone economic and political transformations, with the result that the developed countries dominate the global economy.

Strategic thinking should be useful only when it supports strategic thinking and leads to strategic management "the foundation of an effective institution". Strategic thinking means, "Do we do the right thing?" It entails the following three variables: A specific purpose, an understanding of the environment, especially forces that influence or support the achievement of that purpose, as well as creativity in developing effective responses to those forces and constraints. Strategic management is the application of strategic thinking in corporate leadership and focuses on the future in a context of changes but in a relatively predictable environment.

\section{Recommendation}

Through research and analysis in this study and the results, a set of recommendations emerges that can be developed and adopted in the future:

1. Activating the social planning system and reformulating strict laws and regulations in developing countries

2. Developing countries should promote the principle of transparency and democracy

3. Social and economic institutions must be organized within developing countries, in order to arrive at sound planning

4. It is better to activate the strategic planning system in government and private institutions in developing countries, in order to organize society

\section{Authors Contributions}

Khalil Abu Allan: Finding an idea for the study, working on collecting data from sources and references, arranging information and sorting data and starting to analyze the factors and topics that the study contained, approving the sturdy results and fully evaluating the subject matter.

Hassan Qaddumi: Analyzing the reasons that led to the emergence of the study problem and building the criteria upon which the study relied by relying on the analytical approach and the model of developing countries as a case study.

\section{Ethics}

This article is original and contains unpublished material. The corresponding author confirms that all of the other authors have read and approved the manuscript and no ethical issues involved. 


\section{References}

Ahmed, B., 2007. Introduction to social planning. College of Literature. Sana'a University, Yemen.

Aloni, M., 2019. Strategic planning and teamwork, entrepreneur magazine.

Ameri, M., 2005. Stages of strategic planning.

DD, 2007. Strategic planning. Development Department, Wiki University.

Hamo, J., 2016. Ways of change in developing countries (economic development, political development, social development).

Hamza, A., 2019. Social planning. Al-Maisara for Publishing and Distribution, Amman, Jordan.

Kansas UN, 2017. Social planning and policy change. Strategies Section, University of Kansas.

Khalil, A., 2011a. Integration of sectoral planning and regional planning and its role in forming an integrated economic system in the administrative area Example: Nahr el-Bared area in the Ghab region. University of Damascus.
Khalil, M., 2011b. Social planning in contemporary society. Modern University Office, Alexandria, Egypt.

LS, 2019. Systematic strategic planning is the basis of excellence. Al Bayan Bulletin, Localities Section.

PST, 2016. Social planning social study. Platform for Science, Technology.

Qasim, A., 2016. The concept of planning and its importance, types and stages. Scientific and Educational Horizons Website, Department of Educational Planning, Education. Jordan.

Quraishi, A., 2011. Social planning (concept and principles). University of Babylon. Iraq.

RNB, 2017. Planning and developing countries, models. Riyadh Newspaper Bulletins, Al-Riyadh Newspaper. Issue 212.

Whelan, D., 2018. Analysis of Asian sustainable development, china today.

Zu'bi, M., 2018. Underdevelopment and progress in developing countries and the Arab world-dialectic of cause and effect. Ibn rushd foundation for free thought. 